\title{
Recipe for success?
}

1. Take one eager young SHO.

2. Simmer for 2 years and expose to numerous specialities relevant to general practice.

3. Place for 1 year as a GP Registrar in a beacon practice in order to understand the complexities of working with a culturally diverse, deprived inner-city population.

4. Bring to boil, and hone clinical, interpersonal, and organisational skills.

5. Add a soupcon of out-of-hours experience for good measure.

6. You will know when the trainee is ready, as they will have passed the necessary exams and ticked every box on the e-portfolio.

7. Finally remove lid, releasing vast quantities of cash to PMETB, and allow the newly-qualified GP to embark on a fulfilling career, ideally in a local practice.

But is it just me, or do I seem a little raw in the middle and singed around the edges?

I will be reaching the end of my VTS at the beginning of October and I find myself in the unexpected situation of staring into an abyss of unemployment. It seems that there are very few jobs for newly qualified GPs, and that my training 'recipe' has not prepared me for the realities of today's general practice.

Increasing numbers of GPs are being trained (the hospital where I did my VTS now has five times more trainees than 2 years ago) but there is not the concomitant expansion of jobs for these individuals. There is a well known lack of partnership opportunities, but there is also intense competition for salaried, and even locum posts; a recent 6-month maternity locum job in a local practice attracted nearly 50 applicants, a 9-month salaried post, more than 100.

Salaried positions can attract lower pay, less study leave, little or no sickness and maternity leave, but often more clinical work than partners, creating a 'two tier' system. An underclass of young and enthusiastic GPs is being created whose professional development needs are not being met and I fear that it is this group of doctors who will be forced into the arms of private provider organisations, seek employment abroad, or even find alternative careers.

Don't get me wrong, I love my job, or what I initially perceived to be my job. I firmly believe in the importance of a person-centred holistic primary care with continuity as a central tenet. But can I 'bid', can I 'compete for tenders', do I have an MBA to equip me with the knowledge and jargon to take on Virgin and United Health as we vie to work in practices or even polyclinics?

Sadly, I fear the recipe needs a footnote. To complete your perfect GP, ice with no NHS pension, anti-social working hours and no continuity of care. Don't forget to sweeten with Virgin mobile phone and gym membership. Delicious!

\section{Rachael Tait}

DOI: 10.3399/bjgp08X342480

\section{CLARE GERADA - A RESPONSE}

I am sorry that it appears so grim out there and what response can I make without sounding clichéd? It has been a strange few years and even those, in the 'comfortable' position of partnerships have not had an easy ride.

I know for newly-qualified GPs it seems such an uphill struggle to get a foothold into practices. But, please take heart. There is a lot going on behind the scenes. The College and the GPC are aware of the current difficulties and are lobbying hard to improve both the status and terms of conditions of salaried doctors and also to increase the number of practices taking on new partners.

Times are changing, but what is not changing is the need for good, well-trained family doctors and leaving aside glitches in workforce planning, it is unlikely that any GP will be unemployed for long.

\section{Clare Gerada}

DOI: 10.3399/bjgp08X342499 